\title{
BMJ Open Quality A quality improvement programme to reduce hospital-acquired pressure injuries
}

Poonam Gupta (D , ${ }^{1}$ Shiny Shiju, ${ }^{2}$ Gracy Chacko, ${ }^{2}$ Mincy Thomas, ${ }^{2}$ Asma Abas, ${ }^{2}$ Indirani Savarimuthu, ${ }^{2}$ Emad Omari, ${ }^{2}$ Sara Al-Balushi, ${ }^{3}$ Pulikana Jessymol, ${ }^{2}$ Sunitha Mathew, ${ }^{4}$ Marife Quinto, ${ }^{4}$ Ian McDonald, ${ }^{2}$ William Andrews ${ }^{1}$

To cite: Gupta P,

Shiju S, Chacko G, et al.

A quality improvement

programme to reduce

hospital-acquired pressure

injuries. BMJ Open Quality

2020;9:e000905. doi:10.1136/

bmjoq-2019-000905

Received 29 December 2019

Revised 27 June 2020

Accepted 12 July 2020
Check for updates

(C) Author(s) (or their employer(s)) 2020. Re-use permitted under CC BY-NC. No commercial re-use. See rights and permissions. Published by BMJ.

${ }^{1}$ Quality and Patient Safety, Hamad Medical Corporation, Doha, Qatar

${ }^{2}$ Nursing Department, Hamad medical Corporation, Doha, Qatar

${ }^{3}$ Pharmacy Department, Hamad Medical Corporation, Doha, Qatar

${ }^{4}$ Wound Care Department, Hamad Medical Corporation, Doha, Qatar

Correspondence to Dr Poonam Gupta; dubai.poonam@gmail.com

\section{ABSTRACT}

Background At Heart Hospital in Doha, Qatar $(\mathrm{HH})$, 127 pressure injuries (PI) were identified in 2014, corresponding to an incidence of 6.1/1000 patient-days in first 4 months of 2014. Hospital-acquired pressure injury (HAPI) is one of the most common preventable complications of hospitalisation. HAPI significantly increases healthcare costs, including use of resources (dressings, support surfaces, nursing care time and medications). They also have a significant impact on patients in terms of pain, worsened quality of life, psychological trauma and increased length of stay. Working with the Institute for Healthcare Improvement (IHI), we implemented evidence-based practices in all In patient Units at $\mathrm{HH}$ with the aim of reducing the number of HAPls by $60 \%$ within 2 years.

Methods In collaboration with IHI, our multidisciplinary clinical and risk assessment teams tested several changes and implemented a successful programme. The Surface, Skin inspection, Keep moving, Incontinence and Nutrition bundle was implemented. Signs, turning clocks and PI incidence 'calendars' were used in the units as reminders. Attention was paid to endotracheal tube ties in order to address device-related pressure injuries. Counts of HAPI (incidence) and number of Pls per 100 patients surveyed (prevalence) were prominently displayed. Changes were tested using the Plan-Do-Study-Act methodology. Statistical analysis using the independent t-test was applied to detect the significance of any difference in the incidence of HAPI before and after implementation of the changes.

Results The incidence of HAPI dropped from 6.1/1000 patient-days to $1.1 / 1000$ patient-days, an $83.5 \%$ reduction. The prevalence, based on quarterly survey fell from 9.7/100 patients surveyed to 2.0/100 patients surveyed, a $73.4 \%$ decline.

Conclusions The interventions proved to be successful, reducing the incidence of $\mathrm{Pl}$ by $>80 \%$. The outcomes were sustained over a 4-year period.

\section{INTRODUCTION}

\section{Problem description}

Heart Hospital (HH) teams observed high rates of pressure injuries in 2014. The total number of hospital-acquired pressure injury (HAPI) reported that year was 127. As majority of pressure injuries (PIs) are preventable adverse events ${ }^{1}$ and continue to be a worldwide problem in healthcare despite the availability of guidelines, education and equipment, a commitment was made to examine the issue, identify causes and address the problem as priority.

The prevalence of PI at $\mathrm{HH}$ was, and still is, being reported through the National Database of Nursing Quality Indicators (NDNQI). More than 2000 US hospitals and $98 \%$ of Magnet recognised facilities participate in the NDNQI programme to measure nursing quality and improve their outcomes. NDNQI directs participating institutions to conduct a quarterly survey of all patients to determine the prevalence of PI. In the first quarter of 2014, HH found a prevalence of $6.67 \%$, which far exceeded the NDNQI Magnet benchmark. The benchmark mean for HAPIs for the year 2014 was $1.74 \%$. Other studies have reported a PI prevalence ranging from $4.3 \%$ to $30.8 \% .^{2-7}$

It appeared that the majority of PI occurred in the intensive care units (ICU). For example, in January 2014 there were 24 PIs reported, $>50 \%$ of which occurred in the ICU setting.

\section{Setting}

$\mathrm{HH}$ is a tertiary cardiac facility in Doha, Qatar. This effort began as a pilot project in the Cardio Thoracic Intensive Care Unit (CTICU) in April 2014. The CTICU is a Twelve-bedded unit that serves postcardiac surgery patients. The undertaking was then rolled out to all patient care units, including one other ICU and four high dependency units.

\section{Available knowledge}

A PI is 'a localised injury to skin or underlying tissue, usually over a bony prominence, as a result of pressure or pressure in combination with shear ${ }^{8}$ PIs vary in severity and can be classified into 'stages'. The European 
Table 1 The National Pressure Ulcer Advisory Panel-European Pressure Ulcer Advisory Panel classification system for pressure ulcers ${ }^{8}$

\begin{tabular}{ll}
\hline Stage & Description \\
\hline I & $\begin{array}{l}\text { Non-blanching erythema of intact skin. Differential diagnoses include dermatitis, neurogenic ulcer and } \\
\text { deep tissue pressure injury. }\end{array}$ \\
II & $\begin{array}{l}\text { Partial thickness skin loss including epidermis. Dermis is exposed but intact, or there may be ruptured } \\
\text { blisters. }\end{array}$ \\
III & $\begin{array}{l}\text { Full-thickness skin loss including epidermis and dermis. Adipose tissue may be visible and granulation } \\
\text { tissue can be seen. }\end{array}$ \\
IV & Full-thickness skin and tissue loss which exposes underlying muscle, tendon, bone or ligament. \\
Unstageable & Full-thickness with tissue loss, the extent of which cannot be assessed due to slough or eschar. \\
Deep tissue injury & Intact skin with persistent deep red or maroon discolouration. \\
\hline
\end{tabular}

Pressure Ulcer Advisory Panel classifies them into six stages (table 1).

PIs are an important, often underappreciated patient safety issue, and for the patients themselves, an extremely painful event. Furthermore, they represent a substantial financial burden to the organisation. ${ }^{9}$ The overall costs to the healthcare system include resources such as dressings, support surfaces, cushions and medication, nursing care time for repositioning and assessment, surgery time and associated expense and increased length of stay. PIs have a significant impact on health-related quality of life. They are associated with pain, put the patient at risk for infections and sepsis and may lead to increases in length of stay and mortality. ${ }^{10}$ In addition, they put patients at risk of psychological trauma and worsened post-discharge quality of life, including absence from work. ${ }^{1}$

Regular skin inspection plays a vital role in PI prevention, allowing detection of the earliest signs of PI. Skin should be reinspected during every shift to note changes in colour or texture. Patients with darker skin colour may be at increased risk of PI development ${ }^{11}$ because their skin might not develop the telltale red colour or such colour change may be difficult to identify.

Frequent repositioning is one of the oldest forms of PI prevention and remains important to this day. ${ }^{12}$ Pressure on bony prominences such as the coccyx, trochanters, heels and occiput can be minimised by using turning schedules, for example, every 2 hours, and elevating patients' heels off of the mattress. Turning the patient every 2 hours is based on the studies of tissue interface pressures in healthy volunteers. ${ }^{13} 14$

Management of moisture is thought to be another important factor contributing to the prevention of PI. Supplies should be made available at the bedside of each at-risk patient who is incontinent, in order to help the staff to immediately clean, dry and protect the patient's skin after each episode of incontinence. The IHI Five Million Lives Campaign ${ }^{2}$ recommends to "provide premoistened, disposable barrier wipes to help cleanse, moisturise, deodorise and protect patients from perineal dermatitis due to incontinence'.

\section{Rationale}

After realising that we had a significant problem with PI at HH, a thorough analysis was performed by our improvement task force. This revealed that the majority of the cases were coming from ICUs, where patients were acutely ill and with multiple comorbidities. We also noted a significant number of medical device-related PI reported from these units, caused by endotracheal tubes and oxygen bilevel positive airway pressure/continuous positive airway pressure masks. In addition, due to restricted mobility and other factors like diarrhoea, these patients were more susceptible to PI development.

We hypothesised that there was insufficient awareness of the importance of preventive measures as well as a lack of structure around their application. We theorised that implementation of a bundle approach to apply the already proven preventive measures would result in substantial improvement in their use, and consequently in the prevalence of PI.

\section{Aim}

To achieve a $60 \%$ reduction in hospital acquired HAPI in inpatient units of HH, Doha, by 31 December 2018.

\section{Objectives}

1. To decrease the incidence of HAPI in the inpatient units of $\mathrm{HH}$.

2. To follow evidence-based practices using a multidisciplinary team approach.

3. To adopt preventive strategies for PI rather than resorting to treatment.

\section{METHODS}

\section{Context}

The staff at $\mathrm{HH}$ was relatively new to QI methods. In order to build capacity for improvement, the parent organisation, Hamad Medical Corporation, initiated a collaboration with the Institute for Healthcare Improvement (IHI). The overall effort, Best Care Always, aimed to make improvements in the critical care areas, the general wards and the perioperative care setting. The HAPI work 
we describe in this paper formed a part of the overall effort.

\section{Interventions}

Using the IHI's collaborative model, the project brought together frontline healthcare staff from ICUs and telemetry units. This included nurses, physicians, dietitians, physiotherapists, respiratory therapists, wound care nurses and quality advisors, who formed a highly successful and motivated working collaboration. We did a Pareto analysis with the team and identified some major practice gaps. These included lack of proper assessment using the Braden Scale, non-compliance to preventive measures and unavailability of barrier creams. The Model for Improvement framework was used to drive continuous improvement. Briefly, the Model for Improvement advocates structuring an improvement project by setting an aim statement, defining measures (how will you know that a change is an improvement) and selecting changes worthy of testing. Subsequently, Plan-Do-Study-Act (PDSA) are used to test change ideas.

Risk assessment has long been accepted as a necessary precursor to PI prevention. Early recognition of patients who are at risk of developing PI is an integral part of any prevention strategy. We were already using the Braden Scale to help our healthcare professionals to assess each patient's risk of developing pressure ulcers. ${ }^{15}$ Prior to testing changes, our nurses were re-educated on the proper use of the Braden Scale. Small group education sessions as well as hands-on training were provided. Reinforcement of this education from time to time was also done.

The use of, and education about, the Braden Scale was not considered a test of change as it had been hospital policy for several years. 'PDSA' methodology was therefore not used for this preparatory work. Nonetheless, the effectiveness of the education was tested by posteducational evaluation of recipient knowledge by Nurse Educators.

\section{Changes tested}

Based on the analysis of PIs at HH, several changes were tested.

\section{SSKIN bundle}

The first change was to introduce the 'SSKIN' bundle. The SSKIN bundle includes attention to:

- Surface: make sure that the patient has the right support surface.

- Skin inspection: early and regular inspection.

- Keep the patient moving.

- Incontinence/moisture: keep the patient clean and dry.

- Nutrition/hydration: ensure the patient has the right diet and plenty of fluids.

These are all evidence-based practices with ample supportive literature. ${ }^{816}$ In preparation for SSKIN bundle introduction, all bedside nurses were educated in the bundle elements. Ensuring an implementation that worked at $\mathrm{HH}$ required several tests of change. Most of the elements of the bundle were ensured by using an audit form.

\section{SSKIN bundle audit}

Plan/Do

In order to ensure compliance with the SSKIN bundle, an auditing checklist tool was tested. It was first tested with one nurse and one patient.

\section{Study/Act}

The tool was modified slightly based on feedback from Nurses and was then adopted.

\section{Support surfaces \\ Plan/Do}

Air mattresses were in use for all patients at the beginning of the project, however, heel protectors were not. Therefore, we started using heel protection in the form of padding for all patients who could not easily reposition their legs/feet.

\section{Study/Act}

The use of heel protectors when indicated was added to the bundle audit and proved easy to implement, so the change was adopted.

\section{Turning clock}

Plan/Do

Part of the bundle is to 'keep the patient moving'. For those who cannot move on their own, turning every 2 hours is commonly recommended. To serve as a reminder for the bedside nurse, a 'turning clock' was tested (figure 1).

\section{Study/Act}

The turning clock resulted in much better compliance with regular turning, so was adopted. As it turned out, this clock also served as a reminder for regular skin inspection. Based on learning from this test, the turning schedule was synchronised with other patient care activities that involve turning, for example, a morning portable chest X-ray.

\section{Barrier cream \\ Plan/Do \#1}

A proper barrier cream was not in widespread use at the start of this effort. In fact, it was in short supply. The initial test was to use the barrier product (cream or spray) on nasogastric and endotracheal tube securement sites to prevent skin peeling and on dependent areas of patients with incontinence.

\section{Study/Act \#1}

A small supply was secured from the wound care nurses and it was given to the unit head nurses to test on few patients.

The product appeared to be effective, so it was adopted for limited use until more supply could be obtained. 


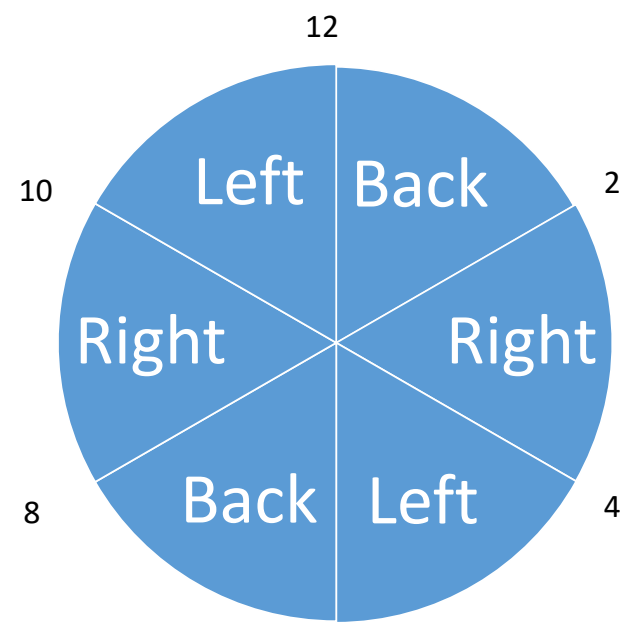

6

Figure 1 Pressure injury prevention turning clock.

Later on, with assistance from hospital leadership, barrier cream became a regular Stores item.

\section{Nutritional assessment}

Poor nutritional status also contributes to the development of PI. ${ }^{3} 1718$ We included a dietitian on our PI Task Team in order to advise on the nutritional needs of patients. Patients at risk for PI often have higher than usual caloric needs and different nutrient requirements. Those with PIs need extra protein in order to heal the wound. Prior to this project, dietitian referrals were only made by physician order for high-risk patients as per the Nursing Nutritional Screening Score.

\section{Plan/Do}

For this effort, the dietitian made rounds on every patient and 'self-referred' (a physician order was still required) for those she deemed to be at high risk. This made it sure that each at-risk patient had a nutrition plan in place.
Table 2 Different change ideas tested as PDSA for visual reminders

\begin{tabular}{lll}
\hline Change tested & Plan/Do & Study/Act \\
\hline $\begin{array}{l}\text { Wrist band } \\
\text { A wrist band similar to the ID band, but in a } \\
\text { different colour, was used to identify high-risk } \\
\text { patients. }\end{array}$ & $\begin{array}{l}\text { Several staff members were confused, as in } \\
\text { many cases this was a third wrist band, next to } \\
\text { ID and allergy bands. }\end{array}$ \\
$\begin{array}{ll}\text { Coloured dot on medical } \\
\text { record }\end{array}$ & $\begin{array}{l}\text { Prior to the introduction of the EMR (Electronic } \\
\text { Medical Records), a coloured dot was placed records objected, as they already used } \\
\text { on the chart to indicate high risk. }\end{array}$ & $\begin{array}{l}\text { coloured dots for other purposes and, again, } \\
\text { there was confusion. }\end{array}$ \\
$\begin{array}{ll}\text { Coloured dot with PI written } \\
\text { on it }\end{array}$ & $\begin{array}{l}\text { To differentiate from other marks on the chart, } \\
\text { the initials 'Pl' were added to the dot. }\end{array}$ & $\begin{array}{l}\text { This proved quite cumbersome and was } \\
\text { abandoned. }\end{array}$ \\
$\begin{array}{l}\text { Sticker on patient's room } \\
\text { door }\end{array}$ & $\begin{array}{l}\text { Moving the reminder to the patient's door was } \\
\text { tried next. }\end{array}$ & $\begin{array}{l}\text { Again, the PI sticker seemed lost among the } \\
\text { other warning stickers on the doors, such as } \\
\text { infection control precautions and fall risk. }\end{array}$ \\
$\begin{array}{l}\text { Sticker inside room on the } \\
\text { patient's whiteboard }\end{array}$ & $\begin{array}{l}\text { The reminder was next tried on the whiteboard } \\
\text { inside each room where other information } \\
\text { such as expected discharge date is located. }\end{array}$ & $\begin{array}{l}\text { for information, this test finally proved successful } \\
\text { and was adopted. }\end{array}$ \\
\hline
\end{tabular}

$\mathrm{PI}$, pressure injury. 


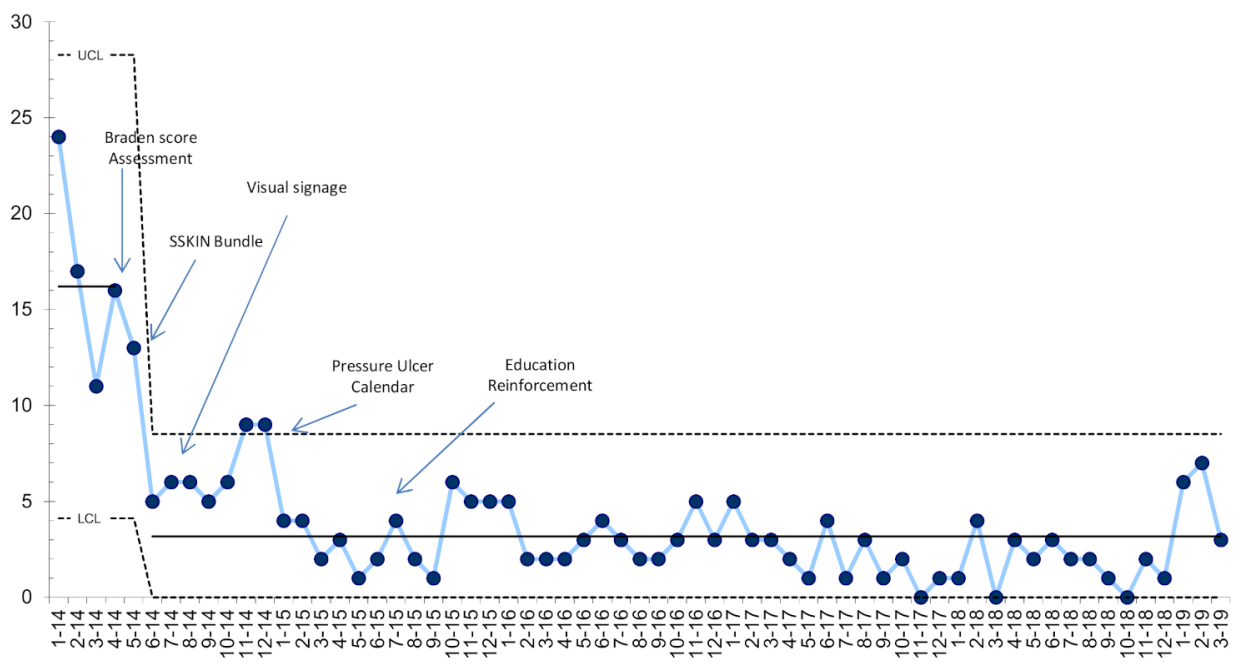

Figure 2 Number of pressure injuries per month. SSKIN, Surface, Skin inspection, Keep moving, Incontinence and Nutrition.

\section{Study/ Act}

The 'self-referral' process resulted in far more at-risk patients being assessed and plans being made. Direct dietitian involvement also improved nutritional practices, for example, discouraging parenteral and encouraging enteral nutrition. The next change planned for testing is to ensure compliance with the institution's Enteral Feeding Guideline.

\section{Device-related pressure injury prevention}

An often overlooked type of PI is related to devices such as nasogastric and endotracheal tubes. We included a respiratory therapist on our team to advise on the prevention of device-related PI. PIs due to the endotracheal tube itself are a major concern, which could be due to failure to follow the manufacturer's recommendations.

\section{Endotracheal tube tie repositioning}

Plan/Do

Endotracheal tube ties were repositioned regularly to prevent device-related PI. We started with following the manufacturer's guidelines. The package insert for the endotracheal tube securement device we use, the Hollister Anchor Fast, recommends that the endotracheal tube be repositioned every 2 hours. ${ }^{19}$

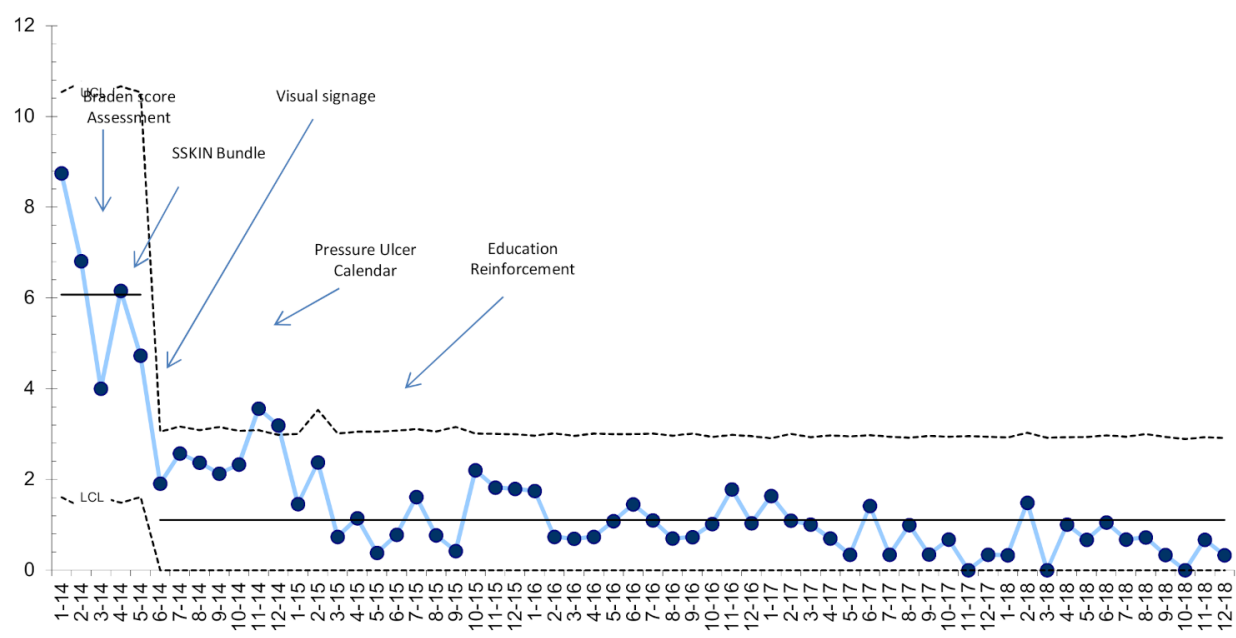

Figure 3 Number of pressure injuries per 1000 patient-days (pressure injury density/incidence rate). SSKIN, Surface, Skin inspection, Keep moving, Incontinence and Nutrition. 


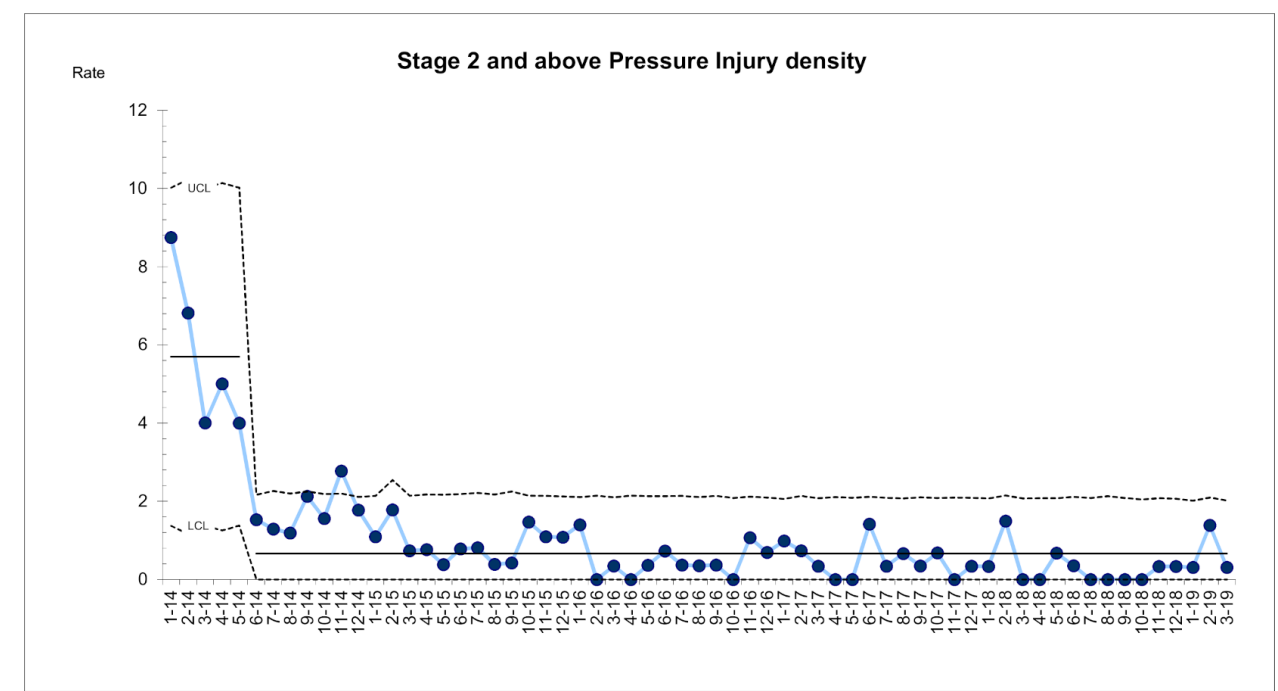

Figure 4 Stage 2 and above pressure injuries per 1000 patient-days (pressure injury density/incidence rate).

\section{Study/Act}

After implementing this approach, device-related PI were reduced, especially stage 1 injuries.

\section{NDNQI Pressure Injury Educational Module}

To further consolidate knowledge about the causes and prevention of PI, each nurse was asked to complete the NDNQI Pressure Injury Educational Module. The successful completion of the module includes a selfassessment, which all nurses were required to complete.

\section{Display of data}

In order to keep performance 'front of mind' and to demonstrate institutional commitment, PI data were displayed in a prominent place, which was also easily accessible by patients and their families.

\section{Plan/Do}

Run charts and other information about the project were displayed in a central location.

\section{Study/Act}

After some time, it became clear that data display using standard QI methodology was not universally understood. Therefore, a 'pressure injury calendar' was posted. This calendar showed, for every day, whether there was a new PI or not on the unit, using a 'smiley face' to indicate 'no PI'. When success began to accrue, the streak of days without a PI became obvious and was very motivational.

\section{PI risk reminders}

A method to make sure all care givers are aware of the patients at high risk (per Braden Score) helps to remind them of the need to execute all components of the SSKIN bundle as well as the other measures we implemented. The evolution of this change nicely demonstrates the use of the PDSA method (table 2). Each of the changes were tested on only one or two patients, with one or two nurses, over 1 or 2 days. This resulted

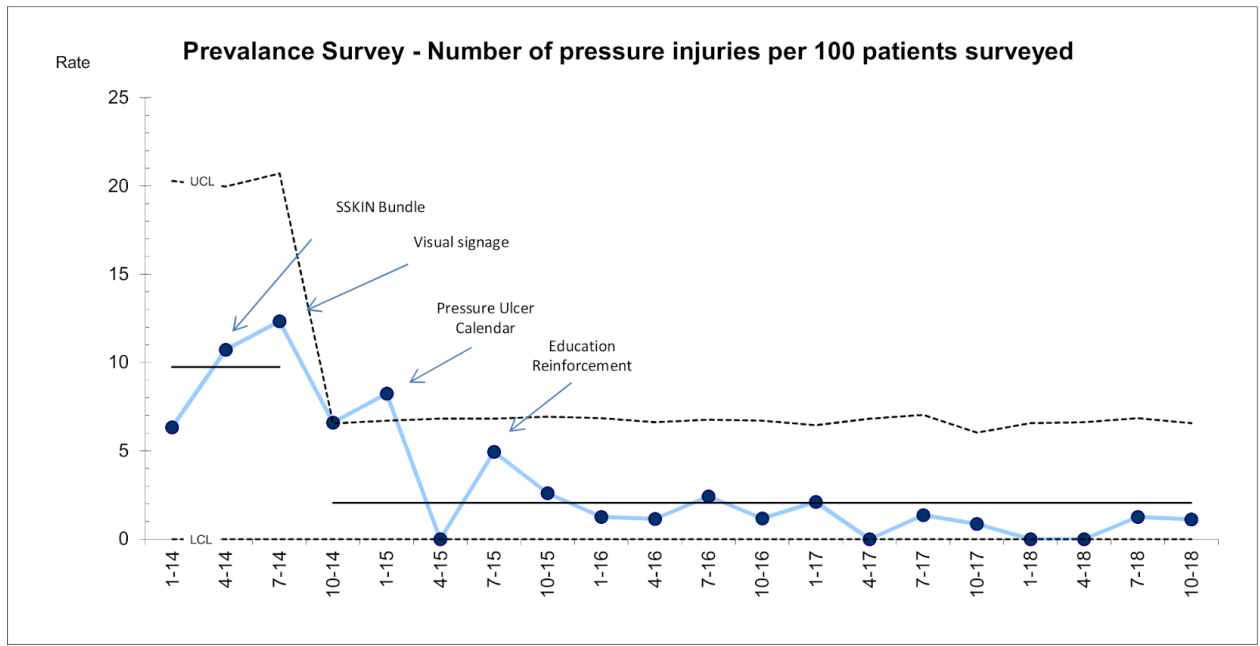

Figure 5 Number of pressure injuries per 100 patients surveyed (prevalence). SSKIN, Surface, Skin inspection, Keep moving, Incontinence and Nutrition. 


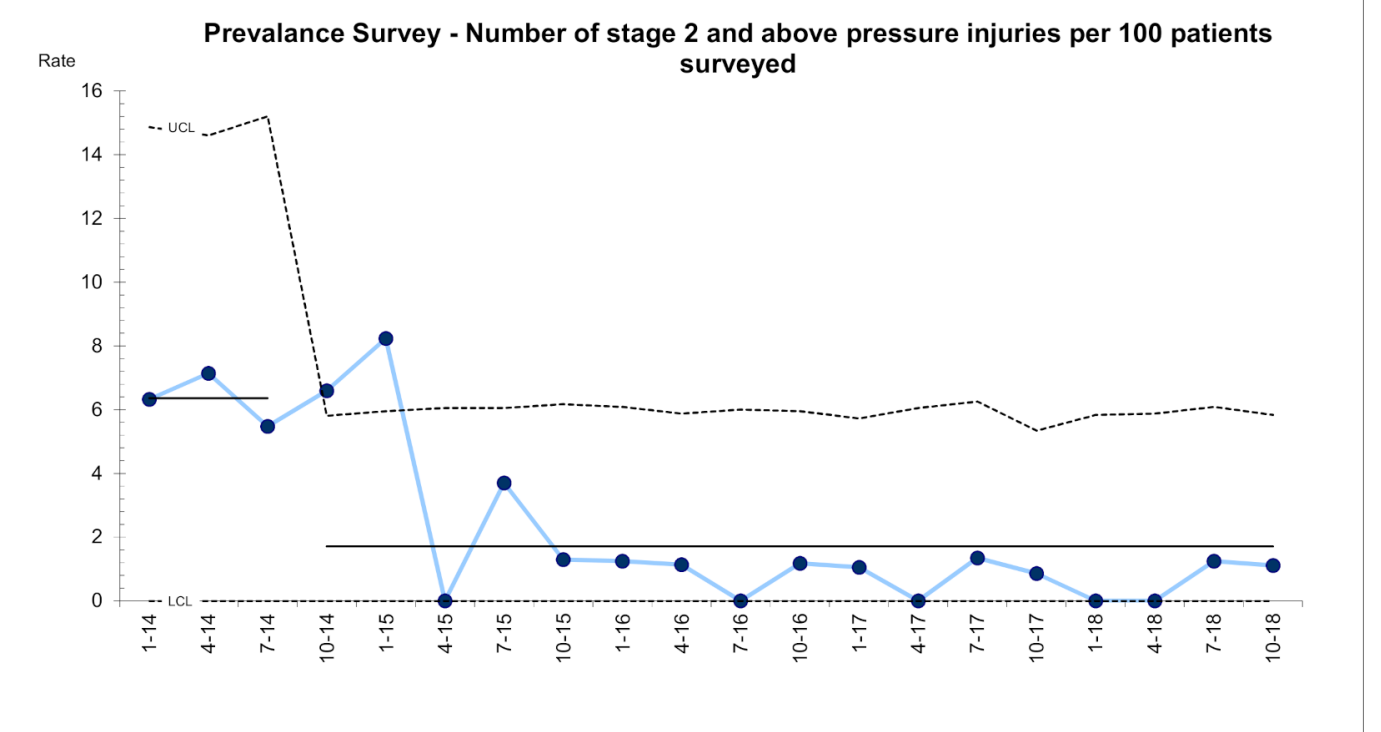

Figure 6 Number of stage 2 and above pressure injuries per 100 patients surveyed.

in an efficient testing of several options, avoiding widespread implementation of an approach that would not work.

\section{STUDY OF THE INTERVENTIONS \\ Outcome measures}

The data collection for PI was done using our incident reporting system. We specifically included stage 1 PI, which in many studies is not reported and/or excluded. Incidence rates were calculated accordingly.

Quarterly prevalence surveys were also conducted hospital-wide, every quarter. All eligible patients were assessed by a task force of experts composed of wound care nurses, quality improvement professionals and frontline staff. Community-acquired PIs are excluded from the data as patients are not infrequently admitted to the facility with PIs.

\section{Process measures}

Each of the changes tested were assessed by qualitative as well as quantitative measures. The compliance with the use of each of the changes was measured for each change, such as per cent compliance with the SSKIN bundle as a whole and for each of the bundle elements, endotracheal tube tie repositioning, education module completion, etc. Equally important were the subjective impressions of the frontline staff on the feasibility and success of each change that was tested.

\section{Analysis}

The outcomes of the project were analysed in two ways. Using standard 'run chart rules' which detect statistically significant changes in outcomes over time, each measure was assessed on a regular basis for significant changes. In addition, using a 'before intervention' and 'after intervention' analysis using Independent Student's t-test, the significance of the outcomes was assessed.

\section{RESULTS}

After spread from the pilot unit to the rest of the facility, this collaborative approach resulted in an $83.4 \%$ reduction in the total number of HAPI reported in all inpatient units.

The annual count of HAPI was reduced from 127 in 2014 to 21 in 2018 (figure 2). The run chart displayed in this figure is annotated to show the progressive implementation of some of the changes tested. It appears that attention to the SSKIN bundle had the biggest impact.

In terms of PI density or incidence rate per 1000 patient-days, it dropped from 6.1 per 1000 patient-days to 1.1 per 1000 patient-days (figure 3 ).

Similarly, the incidence rate of PI stage 2 and above was reduced from 5.7 per 1000 patient-days to 0.7 per 1000 patient-days (figure 4 ). This represents an $87.7 \%$ reduction, even greater than the reduction seen for all PIs. This implies that this approach reduced the incidence of PI, and prevented the progression of stage 1 PI to more advanced PI.

Analysis of the data using the independent t-test showed that the reduction in PI incidence for the 5 months before the intervention (81 PIs over 12354 patient-days) compared with the 5 months after the intervention (28 PIs over 13335 patient-days) was statistically significant $(\mathrm{p}<0.0001)$.

There was also a remarkable reduction in the prevalence of PI as determined by the quarterly survey of every patient in the hospital. Using survey data from 20 quarters, conducted on 1701 patients, we noted a $79.4 \%$ reduction from 9.7 per 100 patients to 2 per 100 patients (figure 5).

For stage 2 and above PI, the prevalence was reduced $73.4 \%$, from 6.4 per 100 patients to 1.7 per 100 patients (figure 6).

These results have been sustained for $>4$ years and the improvement still persists. 


\section{DISCUSSION}

\section{Summary}

During this quality initiative, we achieved remarkable results. The implementation of a 'bundle' of preventive measures resulted in a dramatically greater improvement than our initial aim of $60 \%$. The total number of HAPI reported in 2014 was 127. This was reduced to 21 in 2018, an $83.4 \%$ reduction in incidence. Prevalence by quarterly survey fell from 9.7 per 100 patients surveyed to 2 per 100 patients $(79.4 \%)$. For stage 2 and above PI, we saw a reduction from 6.4 per 100 patients to 1.7 per 100 patients $(73.4 \%)$.

\section{Interpretation}

As can be seen in figure 2, the improvement in PI incidence was progressive over time. By the nature of the methodology, using iterative, sequential improvements across multiple changes that were tested, it is very difficult to say with any confidence which changes were responsible for improvement and how much did a specific change contribute to the overall result. The annotations in the run chart in figure 2 suggest that two of the more important changes were the introduction of the SSKIN bundle and the display of data using the PI incidence calendar.

The project had a profound, though not quantifiable, impact on the hospital staff, especially the nursing staff. Over the course of the Best Care Always project, which included this PI work, the degree of familiarity, indeed competence, with QI methods displayed by frontline staff soared. Along with this, and buoyed by the success of the project, an institutional belief in the power and utility of QI was born and is thriving.

There were many challenges faced during the project. They included:

- A lack of understanding of the risk assessment tool.

- Staff was not aware of their data so there was no sense of urgency, no 'burning platform'.

- There was no appreciation of the importance of device related PI.

- Barrier cream availability was limited.

An important issue that was addressed during the Best Care Always initiative was reluctance to report adverse outcomes. In order to encourage reporting as we tried to promote a 'no blame culture', we attempted to recognise and celebrate staff who overcame their reluctance. Staffs are appreciated for their participation and performance by emails, and celebrating success. Some frontline staffs are rewarded for reporting through recognition during our annual patient caring and safety campaign. Such recognition hopefully increases the confidence of the staff in reporting without fear.

\section{Strengths and lessons learnt}

There are several strengths to this programme:

- Evidence-based healthcare practices were implemented.

- Results have been demonstrably sustained.
- Nurses were educated or had their knowledge refreshed in a multimodal way, using one-on-one interaction, small groups and online seminars.

- The entire approach involved the whole multidisciplinary team.

- Data were made highly visible by displaying it on each unit's quality board.

- Successes and challenges were presented at leadership meetings keeping the profile of the work high.

There were several lessons learnt during the course of this initiative. The first lesson we learnt is how vital it is to involve key stakeholders and a multidisciplinary team right from the start. Initially, this can be difficult but a good start leads to a successful and sustainable outcome. Second, we learnt that frontline staff should be aware of their own unit's data. Unless they are provided with their data, it is really impossible to create any sense of urgency. We provided real-time data to them and they were able to make striking improvement.

Involving our Respiratory Therapy department for medical device-related PI proved a success and we were subsequently able to involve them in other initiatives as well. This initiative has resulted in substantial team building.

\section{CONCLUSIONS}

This initiative demonstrated the value of using a proven quality improvement approach, the model for improvement, including small tests of change in the form of PDSA cycles. These tests allowed us to incorporate evidencebased practice into the daily routine and make a significant difference in patient outcomes. ${ }^{20}$ Our data showed that timely identification and management of PI can halt progression to worse stage PI.

Hospital acquired HAPI represent a significant cost to healthcare facilities. Prevention of PIs is a key, essential part of nursing practice. Unless proper measures are taken for prevention, incidence will likely keep increasing as will associated costs.

This initiative had a positive impact on patients, staff and the whole organisation. For patients it reduced the risk of PIs, resulting in a better quality of life and less time needed in hospital. For the organisation, reduced costs and staff time associated with ulcer treatment, and fewer extended hospital stays. Finally, for the staff, satisfaction of achieving better outcomes for their patients and the acquisition of quality improvement skills to apply to other improvement projects.

Acknowledgements The authors would like to thank Heart Hospital leadership, including Professor William John McKenna (CE0, Medical Director), Mr. Paul Mavin (Executive Director), Mr. Mohd. Al Zubi (Nursing Director), Ms. Fadia Hassan (Asst. Executive Director for Patient Safety), Mr. Othman Otoum (Head of Risk Management), Ms. Catherine Marshal (Nursing Director), Mr. Samir Shamieh (Nursing Director) for their support to this programme. The authors would like to thank Hamad Healthcare Quality Institute (HHQI) and IHI faculty for collaboration during Best Care Always. The authors would specially like to thank Mr. Prasobh Jacob (Physiotherapy), Mr. Ruzzel Galvez (Respiratory Therapy), Ms. Aisha Pookunju 
(Dietary Services), Ms. Kakoli Roy and Ms. Joycee Kurian (Quality Reviewers) and Mr. Mathew Jacob (Corporate Nursing) for their kind assistance to the initiative.

Contributors PG designed and led the study and prepared initial draft of this manuscript. SS, MT, GC, IS and AA contributed by testing and implementing change ideas and data collection. $\mathrm{SM}$ and $\mathrm{MQ}$ assisted in prevalence surveys and providing valuable inputs from wound care point. EO supervised work in high dependency units. IMCD supervised the sustainability of the process. $S A B$ contributed to the analysis and interpretation of the data. WRA played key role in the preparation of the manuscript and providing valuable inputs.

Funding There was no external funding for this project. The overall quality improvement effort 'Best Care Always' was entirely funded by the Hamad Medical Corporation, our parent organisation.

Competing interests None declared.

Patient and public involvement Patients and/or the public were involved in the design, conduct, reporting or dissemination plans of this research. Refer to the 'Methods' section for further details.

Patient consent for publication Not required.

Ethics approval An institutional review board was not sought to review as all of the changes being tested were evidence based and widely accepted internationally. There was no control group and therefore no randomisation, so no patients would be denied this 'best practice' intervention.

Provenance and peer review Not commissioned; externally peer reviewed.

Data availability statement All data relevant to the study are included in the article.

Open access This is an open access article distributed in accordance with the Creative Commons Attribution Non Commercial (CC BY-NC 4.0) license, which permits others to distribute, remix, adapt, build upon this work non-commercially, and license their derivative works on different terms, provided the original work is properly cited, appropriate credit is given, any changes made indicated, and the use is non-commercial. See: http://creativecommons.org/licenses/by-nc/4.0/.

ORCID iD

Poonam Gupta http://orcid.org/0000-0001-8737-8804

\section{REFERENCES}

1 National database of nursing quality IndicatorsTM (NDNQI@). Available: http://www.health-links.me/web/ndnqi.html [Accessed Jun 2020].

2 Institute for Healthcare Improvement. How-to guide: prevent pressure ulcers. Cambridge, MA, 2011. http://www.ihi.org/resources/ Pages/Tools/HowtoGuidePreventPressureUlcers.aspx.
3 Thomas DR, Goode PS, Tarquine PH, et al. HospitalAcquired pressure ulcers and risk of death. J Am Geriatr Soc 1996;44:1435-40.

4 Pinchcofsky-Devin GD, Kaminski MV. Correlation of pressure sores and nutritional status. J Am Geriatr Soc 1986;34:435-40.

5 Thomas DR. The role of nutrition in prevention and healing of pressure ulcers. Clin Geriatr Med 1997;13:497-512.

6 Tannen A, Dietz E, Dassen T, et al. Explaining the national differences in pressure ulcer prevalence between the Netherlands and Germany-adjusted for personal risk factors and institutional quality indicators. J Eval Clin Pract 2009;15:85-90.

7 Kottner J, Dassen T, Lahmann N. Prevalence of deep tissue injuries in hospitals and nursing homes: two cross-sectional studies. Int $J$ Nurs Stud 2010;47:665-70.

8 National Pressure Ulcer Advisory Panel and European Pressure Ulcer Advisory Panel. Prevention and treatment of pressure ulcers: quick reference guide. Washington, DC, 2016. https://www.epuap.org/ wp-content/uploads/2016/10/quick-reference-guide-digital-npuapepuap-pppia-jan2016.pdf

9 Preventing pressure ulcers in hospitals. Are we ready for this change? agency for healthcare research and quality. Rockville, MD. https://www.ahrq.gov/patient-safety/settings/hospital/resource/ pressureulcer/tool/pu1.html. (Accessed June 2020).

10 Osuala E. Innovation in prevention and treatment of pressure ulcer: nursing implication. Trop J Med Res 2014;17:61-8.

11 National Pressure Ulcer Advisory Panel. NPUAP pressure ulcer Stages/Categories. Available: www.npuap.org/resources/ educational-and-clinical-resources/npuap-pressure-ulcerstagescategories/ [Accessed Jun 2020].

12 Norton D, McLaren R, Exton-Smith AN. An investigation of geriatric nursing problems in hospital. New York: Churchill Livingstone, 1962.

13 Kosiak M. Etiology and pathology of ischemic ulcers. Arch Phys Med Rehabil 1959;40:62-9.

14 Kosiak M. Etiology of decubitus ulcers. Arch Phys Med Rehabil 1961:42:19-29.

15 Bergstrom N, Braden BJ, Laguzza A, et al. The Braden scale for predicting pressure sore risk. Nurs Res 1987;36:205-10.

16 NHS Midlands and East. Stop the pressure pathway, 2012. Available: nhs.stopthepressure.co.uk [Accessed Jun 2020].

17 Berlowitz DR, Wilking SV. Risk factors for pressure sores. A comparison of cross-sectional and cohort-derived data. J Am Geriatr Soc 1989;37:1043-50.

18 Pinchcofsky-Devin GD, Kaminski MV. Correlation of pressure sores and nutritional status. J Am Geriatr Soc 1986;34:435-40.

19 Hollister Inc. Anchor Fast [package insert]. Libertyville, IL: Hollister Inc, 2009.

20 Titler MG, Kleiber C, Steelman V, et al. Infusing research into practice to promote quality care. Nurs Res 1994;43:307-13. 